\title{
Dormência em Sementes de Guandu (Cajanus cajan (L.) Millsp)*
}

\author{
Rodolfo Godoy ${ }^{1}$, Francisco Humberto Dübbern de Souza ${ }^{2}$
}

\begin{abstract}
RESUMO - O ensaio foi conduzido para estudar a ocorrência de dormência, expressa em porcentagem de sementes duras, em sementes de 17 linhagens e três cultivares comerciais de guandu. As sementes foram colhidas, debulhadas manualmente e armazenadas em sacos de papel em câmara a $10^{\circ} \mathrm{C}$ e $25 \%$ de umidade relativa do ar. Foram efetuados testes de germinação com quatro repetições de 50 sementes, após um, dois, três, quatro, cinco, nove, doze e quinze meses de armazenamento. Não foram observadas sementes duras em oito linhagens e nas três cultivares comerciais. Entre essas, a linhagem g58-95 apresentou baixo potencial de armazenamento, com queda rápida de seu poder germinativo. Por outro lado, a linhagem g184-97 apresentou baixo percentual de sementes duras, as linhagens g3-94, g6-95 e g124-95 praticamente mantiveram os percentuais iniciais, as g101-97, g127-97, g154-95 e g167-97 apresentaram aumento no percentual de sementes duras até nove meses de armazenamento e a g27-94, constante decréscimo. Concluiu-se que genótipos de guandu variam amplamente entre si quanto ao caráter ‘produção de sementes duras’ e que a germinação de suas sementes pode depender de escarificação química ou mecânica.
\end{abstract}

Palavras-chave: armazenamento, Fabaceae, forrageira, sementes duras

\section{Dormancy on Pigeon Pea Seeds (Cajanus cajan (L.) Millsp)}

\begin{abstract}
An experiment was conducted to study seed dormancy (hardseedness) in seventeen genetic lines and three commercial cultivars of pigeon pea. The seeds were hand-harvested, hand-shelled, and stored in paper bags in a chamber with $10^{\circ} \mathrm{C}$ and $25 \%$ air relative humidity. Four replications of fifty-seed samples were put to germinate in moist paper rolls at $30^{\circ} \mathrm{C}$, after one, two, three, four, five, nine, twelve and fifteen months of storage. No hard seeds were observed among eight lines and the three commercial cultivars. Among these lines, g58-95 had low storage potential, quickly losing germination percentage. Line g184-97 presented low percentage of hard seeds, lines g3-94, g6-95 and g124-95 kept the initial percentage, g101-97, g127-97, g154-95 and g167-97 had the percentage of hard seeds increased from one to nine months of storage, and percentage of hard seeds of line g27-94, constantly decreased. It was concluded that pigeon pea genotypes vary amply among themselves in terms of hard seed production potential and that satisfactory germination of its seed lots may require artificial chemical or mechanical scarification.
\end{abstract}

Key Words: storage, hard seeds, forage crop, Fabaceae

\section{Introdução}

A Embrapa Pecuária Sudeste (São Carlos, SP) vem desenvolvendo, desde 1988, projeto de avaliação e seleção de genótipos de guandu [Cajanus cajan (L.) Millsp] forrageiro. Em determinadas etapas de sua execução, as avaliações foram dificultadas pela presença, em algumas linhagens, de altos percentuais de sementes duras. Apesar de estar associada à perenização de populações de plantas de leguminosas em pastagens (Argel \& Paton, 1999), esta característica pode acarretar problemas em lavouras comerciais, seja pela dificuldade de erradicação da espécie, face ao acúmulo de sementes duras no solo, seja pela dificuldade na obtenção de emergência homogênea e uniforme em áreas plantadas com esta espécie. A dormência em sementes de leguminosas, em geral, é assunto relativamente bem estudado. A proporção de sementes duras produzidas varia de ano para ano e de local para local (Quinlivan, 1967; Clements, 1977). Em várias espécies de leguminosas, a dormência diminui à medida que as sementes envelhecem e a taxa de superação da dormência varia com a espécie (Nakamura, 1962). A diminuição da dormência é favorecida por altas temperaturas, alternância de temperaturas e atmosfera úmida. Segundo Baciu-Miclaus (1970), a umidade relativa do ar na fase final da maturação da semente tem grande efeito sobre a produção de sementes duras em soja. Ramsay (1997) verificou que, em Vicia faba (L.), a dormência de sementes é caráter herdável, monogênico e de herança simples.

\footnotetext{
1 Pesquisador da Embrapa Pecuária Sudeste - Caixa Postal 339 - 13560-970 - São Carlos, SP. E-mail: godoy@cppse.embrapa.br

2 Pesquisador da Embrapa Pecuária Sudeste - Caixa Postal 339 - 13560-970 - São Carlos, SP. E-mail: fsouza@cppse.embrapa.br

* Trabalho parcialmente financiado pela Unipasto - Associação para o fomento à pesquisa de melhoramento de forrageiras tropicais.
} 
Entretanto, os trabalhos com sementes de guandu são escassos e divergentes entre si. Skerman (1977) afirma que a porcentagem de sementes duras em guandu é inferior a 10\%, não sendo necessário tratamento de quebra de dormência para o plantio. A mesma opinião foi expressa por Seiffert (1982), segundo o qual sementes de guandu não necessitam ser escarificadas antes do plantio, pois, em geral, a porcentagem de sementes duras é baixa. Entretanto, Rao et al. (1982) encontraram grandes diferenças no potencial de armazenamento, entre genótipos de guandu.

Objetivou-se, com o presente trabalho, verificar a presença de sementes duras e seu comportamento durante o armazenamento, em 17 linhagens puras selecionadas e três cultivares comerciais de guandu.

\section{Material e Métodos}

Em ensaio de avaliação agronômica de 17 acessos de guandu forrageiro, com quatro repetições em blocos ao acaso, instalado em São Carlos (SP), lat.

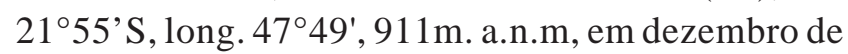
1998, com três cultivares comerciais como testemunhas, um bloco completo foi reservado para avaliações de ciclo vegetativo e características morfológicas, não tendo sido cortado. Sementes maduras desses 20 genótipos foram colhidas em várias ocasiões: g58-95 em 18/05/1999; g17-94 em 04/06/1999; g6-95, g18-95, g47-94 e g66-95 em 21/ 06/1999; g27-94 em 02/07/1999; g184-97, g29b-94 e g154-95 em 13/07/1999; g146-97, g167-97, g101-97e g3-94 em 23/07/1999 e g124-95 e g127-97, em 28/07/ 1999. As sementes de todas as linhagens foram obtidas de vagens totalmente secas, colhidas individualmente nas plantas; em seguida, foram debulhadas e limpas manualmente, submetidas à secagem ao sol, como forma de uniformizar seus teores de água, e armazenadas em sacos de papel, a $10^{\circ} \mathrm{C}$ e $25 \%$ de umidade relativa. Após um, dois, três, quatro, cinco, nove, doze e quinze meses de armazenamento, amostras dessas sementes foram retiradas e submetidas à teste de germinação, com quatro repetições de 50 sementes, em germinador, a $30^{\circ} \mathrm{C}$, em rolos de papel especial para germinação. Foram feitas contagens de número de plântulas normais, anormais e de sementes mortas e duras, aos cinco e dez dias após a instalação do teste, e os totais transformados em porcentagens. Nestas avaliações, foram utilizados os conceitos e definições das Regras para Análise de
Sementes (BRASIL, 1992) e foram consideradas sementes duras as que, ao final dos testes, permaneciam sem absorver água. Os resultados permitiram classificar as linhagens estudadas em dois grupos, de acordo com a presença ou não de sementes duras. Para cada grupo, as porcentagens de plântulas normais e de sementes duras, quando foi o caso, foram submetidas à análise estatística. Para todos os casos, a análise de variância revelou significância para a interação acessos x período de armazenamento. Foi, então, efetuada análise de variância dos dados de períodos de armazenamento para cada acesso, sendo as médias comparadas entre si pelo teste Tukey, a $5 \%$ de probabilidade.

\section{Resultados e Discussão}

Embora de grande importância para o armazenamento de sementes, o teor de água, face aos procedimentos adotados na colheita e processamento neste caso, provavelmente não influenciou o comportamento dos diferentes lotes quanto às porcentagens de germinação e de sementes duras. As cultivares Anão, Caqui e Fava Larga e as linhagens g17c-94, g18-95, g19b-94, g29b-94, g47-94, g58-95, g66-95 e g146-97, não apresentaram sementes duras. Consta na Tabela 1 a porcentagem de plântulas normais dentro de cada período de armazenamento, para cada acesso. Pode-se considerar que, no grupo composto pela cultivar Caqui e pelas linhagens g17c-94, g19b-94, g29b-94, g47-94 e g146-97, não houve queda no poder germinativo, pois não houve diferenças significativas $(P>0,05)$ entre a primeira e a última avaliação. As demais linhagens e cultivares parecem ter diferentes potenciais de armazenamento: a g58-95 é a de menor potencial, pois apresentou perda de poder germinativo após apenas dois meses de armazenamento; as linhagens g17c-94 e g66-95 apresentaram queda de poder germinativo após nove meses; a Fava Larga, após doze meses; e a cv. Anão e a linhagem g18-95, após quinze meses. Isso indica que, caso alguma dessas linhagens venha a ser lançada como nova cultivar, cuidados maiores devem ser tomados no armazenamento de suas sementes. Essa diferença de comportamento observada entre genótipos durante o armazenamento é semelhante aquela relatada por Rao (1982).

Nas Tabelas 2 e 3, encontram-se, respectivamente, as porcentagens de plântulas normais e de sementes duras de todas as linhagens que apresentaram 


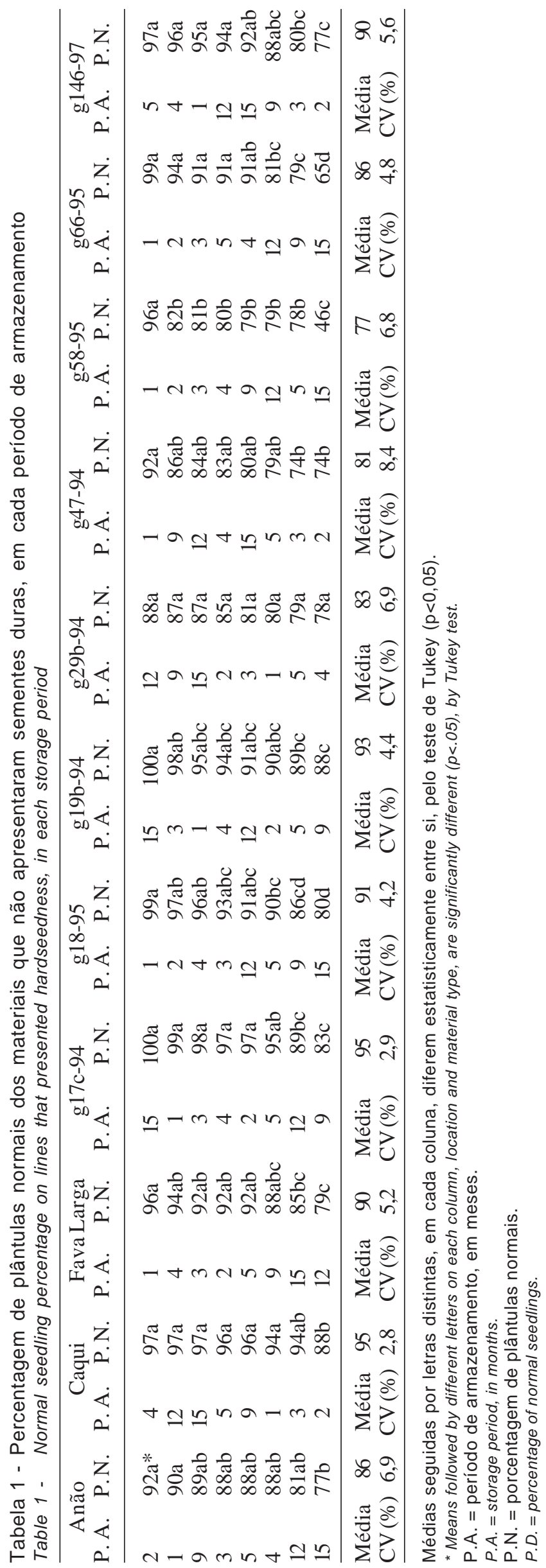

dormência, mesmo que representada por pequenos percentuais, em cada período de armazenamento. As linhagens g3-94, g6-95, g101-97, g127-97, g154-95 e g167-97, embora com níveis iniciais e finais de dormência diferentes, apresentaram aumento significativo $(\mathrm{P}<0,05)$ no percentual de sementes duras até nove meses de armazenamento, a partir do que houve decréscimo. A linhagem g27-94 apresentou percentuais de sementes duras constantes até o $5^{\circ}$ mês, a partir do que houve decréscimo. Isso significa que as condições ambientais de armazenamento $\left(10^{\circ} \mathrm{C}\right.$ e $25 \%$ U.R.) influenciaram de alguma forma o grau de impermeabilidade do tegumento; este fenômeno foi relatado em várias espécies de leguminosas de clima temperado (Owen, 1956). As sementes da linhagem g124-95, entretanto, apresentaram percentuais praticamente constantes de sementes duras. Em função do decréscimo do percentual de sementes duras, a porcentagem de plântulas normais das linhagens g27-94 e g167-97 aumentou com o período de armazenamento, ao contrário do que ocorreu com as demais linhagens, cuja porcentagem de sementes viáveis mantiveram-se praticamente estáveis durante o período.

Verifica-se, na Figura 1, o percentual de sementes duras das linhagens g3-94, g27-94 e g184-97, representando os três tipos observados de comportamento durante o armazenamento. A proporção de sementes duras produzidas pelas plantas variou entre os genótipos comparados de maneira idêntica à observada em soja por Tinius \& Hinson (1987) e atribuída a interações entre genótipo e ambiente. A taxa de permeabilidade do tegumento, entretanto, é determinada apenas pelo genótipo (Tinius, 1991), pois, quando submetidas à idênticas condições ambientais específicas, genótipos de plantas leguminosas variam quanto à velocidade de superação da dormência imposta pelo tegumento. Genótipos de leguminosas forrageiras, inclusive tropicais, variam amplamente entre si quanto a requisitos específicos de temperatura necessários à superação da dormência imposta por tegumento impermeável (McDonald, 2002).

Verifica-se que o observado nos grupos representados por g3-94 e g27-94 contraria as opiniões de Skerman (1977) e Seiffert (1982), que a porcentagem de sementes duras em guandu, por serem baixas, dispensam tratamentos para quebra de dormência de amostras de sementes destinadas ao plantio. De fato, algumas das linhagens estudadas deverão ser tratadas para a quebra da dormência antes do plantio, caso

R. Bras. Zootec., v.33, n.6, p.2201-2205, 2004 (Supl. 3) 

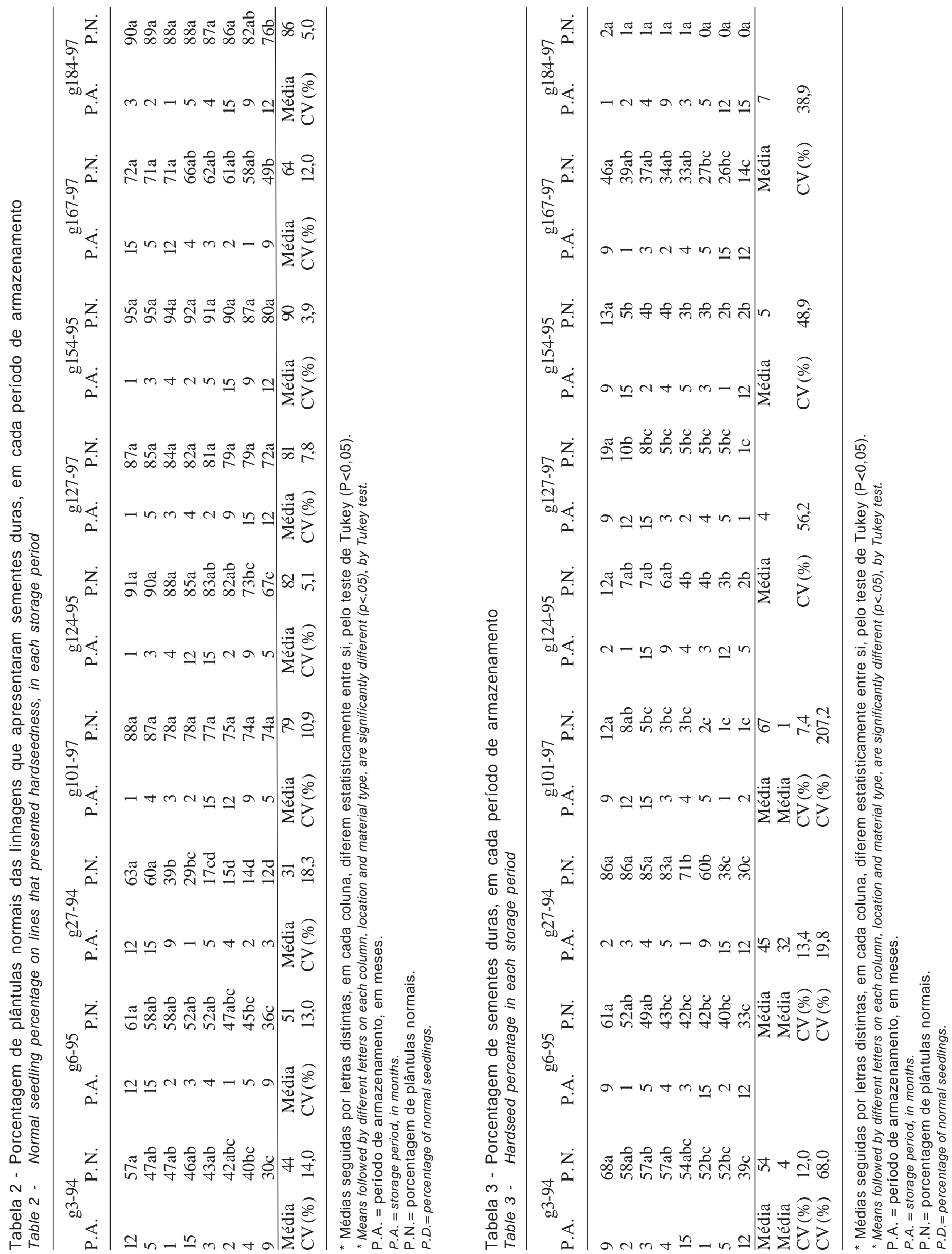


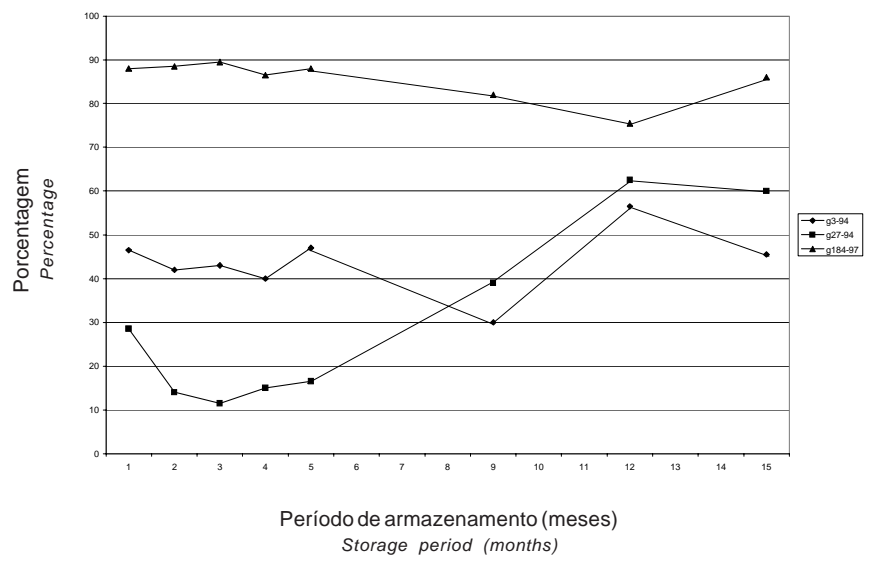

Figura 1 - Porcentagem de sementes duras das linhagens g3-94, g27-94 e g184-97.

Figure 1 - Percentage of hard seeds on lines g3-94, g27-94 and g184-97.

venham a ser lançadas como novas cultivares. Várias alternativas físicas e químicas para este processo são discutidas por Argel \& Paton (1999).

Aumento da proporção de sementes dormentes durante o armazenamento, idêntico ao apresentado pela linhagem g27-94 foi relatado por Evans e Smith (1999), que atribuíram o fenômeno ao estabelecimento de dormência embrionária, fisiológica, estimulado por condições de baixa temperatura e umidade relativa do ar do ambiente.

\section{Conclusões}

Sementes de diferentes genótipos de guandu diferem entre si quanto ao potencial de armazenamento e à capacidade de produzir sementes duras.

\section{Literatura Citada}

ARGEL, P.J.; PATON, C.J. Overcoming legume hardseededness. In: LOCH, D.S.; FERGUSON, J.E. (Eds.) Forage seed production: tropical and sub-tropical species. Wallingford: CAB International, 1999. v.2, p.247-265.

BACIU-MICLAUS, D. Contribution to the study of hard seed and coat structure properties of soybean. Proceedings of the International Seed Testing Association, v.35, n.2, p.599-617, 1970.
BRASIL. Ministério da Agricultura e da Reforma Agrária. Regras para análise de sementes. Brasília: Departamento Nacional de Produção Vegetal, Divisão de Sementes e Mudas, 1992. 365p.

CLEMENTS, R.J. Agronomic variation in Centrosema virginianum in relation to its use as a subtropical pasture plant. Australian Journal of Experimental Agriculture and Animal Husbandry, v.17, p.435-444, 1977.

EVANS, P.M.; SMITH, F.A. Patterns of seed softening in subterranean clover in a cool, temperate environment. American Journal, v.91, p.122-127, 1999.

McDONALD, C.K. Variation in the rate of hard seed breakdown of twelve tropical legumes in response to two temperature regimes in the laboratory. Australian Journal of Experimental Agriculture, v.40, p.387-396, 2002.

NAKAMURA, S. Germination of legume seeds. Proceedings of the International Seed Testing Association, v.27, n.3, p.694-709, 1962.

OWEN, E.B. The storage of seeds for maintenance of viability. Commonwealth Bureau of Pastures and Field Crops. Hurley: 1956. 81p. (Bulletin 43)

QUINLIVAN, B.J. Environmental variation in the long term pattern of germination from hard seeds of Lupinus varius. Australian Journal of Experimental Agriculture and Animal Husbandry, v.7, p.263-265, 1967.

RAMSAY, G. Inheritance and linkage of a gene for testa-imposed seed dormancy in faba bean (Vicia faba L.). Plant Breeding, v.116, p. 287-289, 1997.

RAO, N.K.; Van der MAESEN, L.J.G.; REMANANDAN, P. Seed viability of pigeon-pea stored in two environments. Netherlands Journal of Agricultural Science, v.30, p.99-103, 1982.

SEIFFERT, N.F. Leguminosas para pastagens no Brasil Central. Brasília: EMBRAPA-DID, 1982. 31p. (EMBRAPA-CNPGC. Documentos, 7)

SKERMAN, P.J. Cajanus spp. In: SKERMAN, P.J. (Ed.) Tropical Forage Legumes. Rome: FAO, 1977. p.485-493.

TINIUS, C.N. Variable expression of seed coat permeability. Soybean Genetics Newsletter, v.18, p.256-259, 1991.

TINIUS, C.N.; HINSON, K. Near-isolines which differ in seed coat permeability. Soybean Genetics Newsletter, v.15, p.170-172, 1987.

Recebido em: 03/09/03

Aceito em: 09/07/04 